\title{
O consumo de frutas nativas no litoral norte do Rio Grande do Sul: modo de vida rural em (re) construção
}

\author{
The native fruits' consumption of north coast of Rio Grande do Sul: the rural way of life in (re)construction
}

\begin{abstract}
Gabriela Pacheco Carniel
Eliziane Nicolodi Francescato Ruiz

Vanuska Lima da Silva

Universidade Federal do Rio Grande Sul - UFRGS - Porto Alegre - Rio Grande do Sul - Brasil

Resumo: $O$ objetivo deste trabalho é apresentar elementos que marcam a construção de identidades e pertencimentos rurais tendo como pano de fundo o consumo de frutas nativas em uma comunidade rural do litoral norte do Rio Grande do Sul que tem sua paisagem composta por tal vegetação. A pesquisa foi realizada através de uma técnica de pesquisa qualitativa conhecida como grupo focal com 11 participantes da comunidade. Os participantes contaram a história da comunidade relembrando o passado, falando do presente e das perspectivas do futuro, partindo sempre das relações com as frutas nativas. As histórias das frutas se relacionam com as histórias de vida da comunidade. As espécies frutíferas nativas são um símbolo da identidade do local, da cultura e de resistência da comunidade. A fala dos interlocutores demonstra elementos como a família, o contato com a natureza e o trabalho com a terra como fatores que contribuem para a formação da identidade da comunidade rural. Como consideração final, apreende-se que o resgate das frutas nativas é uma forma de preservar a paisagem, o ambiente, a cultura e a história do local e também de valorizar esta comunidade rural.
\end{abstract}

Palavras-chave: Frutas nativas. Rural. Identidade.

Abstract: The objective of this study is to present elements that define the construction of rural identities and belongings, taking as a background the consumption of native fruits in a rural community of the north coast of Rio Grande do Sul, that naturally has its landscape composed of such vegetation. The research was carried out through a qualitative research technique known as focal group with 11 community participants. The participants told the history of the community, recalling the past, talking about the present and future perspectives, always starting from relationships with native fruits. Stories of fruits are related to community life stories. Native fruit species are a symbol of local identity, culture and community resistance. The speech of the interlocutors demonstrates elements such as family, 
contact with nature and work with the land as factors that contribute to the identity formation of the rural community. As a final consideration, it is understood that the rescue of the native fruits is a way of preserving the landscape, the environment, the culture and history of the place and also to value this rural community

Keywords: Native fruits. Rural. Identity

\section{Introdução}

A realização deste trabalho parte do anseio por conhecer e dar visibilidade aos elementos que marcam a construção de identidades e pertencimentos rurais tendo como pano de fundo o consumo de frutas nativas em comunidades que, naturalmente, teriam sua paisagem composta por tal vegetação. Como sugere Wanderley (2001) o mundo rural mantém particularidades históricas, sociais, culturais e ecológicas, que o recortam como uma realidade própria, da qual fazem parte, inclusive, as próprias formas de inserção na sociedade que o engloba. Também é particular a forma de se alimentar dessa população, lembrando que a alimentação é um símbolo de uma identidade, atribuída e reivindicada, por meio da qual os homens podem se orientar e se distinguir (MACIEL, 2005).

Em se tratando do consumo de alimentos, vale destacar que mais do que hábitos e comportamentos alimentares, o alimento implica formas de perceber e expressar um determinado modo ou estilo de vida que se quer particularizar a um determinado grupo (MACIEL, 2005). Assim, o que é ingerido serve para nutrir o corpo, mas também sinaliza um pertencimento, servindo como um código de reconhecimento social. $\mathrm{Na}$ alimentação humana, natureza e cultura se encontram, pois, sendo comer uma necessidade vital, o quê, quando e com quem comer são aspectos que fazem parte de um sistema que implica atribuições de significados ao ato alimentar. Assim, estando a alimentação humana impregnada pela cultura, é possível pensar os sistemas alimentares como sistemas simbólicos em que códigos sociais estão presentes atuando no estabelecimento de relações dos homens entre si e com a natureza (MACIEL, 2005).

Nesse sentido, sabendo que a comida é uma forma de comunicação, assim como a fala, e que pode também contar histórias (AMON; MENASCHE, 2008) parto deste princípio e utilizo a comida, mais especificamente as frutas nativas, seus usos e preparações, para perguntar e contar sobre ruralidades, mais especificamente de um espaço do Litoral Norte do Rio Grande do Sul: Qual a história, o modo de viver e valores a serem preservados pelos moradores do distrito da Fortaleza, área rural da cidade de Cidreira, no Litoral Norte do Rio Grande do Sul?

O meio rural mudou muito nos últimos anos, principalmente pelo seu esvaziamento. No caso do Rio Grande do Sul, o movimento migratório foi provocado pelo deslocamento da população em busca de melhores condições de vida, decorrente da transformação experimentada pelo Estado na sua atividade agrícola, a qual foi influenciada pela introdução massiva da mecanização no campo devido especialmente aos cultivos de soja e arroz (BRASIL, 1997). O meio rural nos dias atuais não apresentaria atrativos para a permanência dos jovens no campo. Os indicadores mostram que cada vez mais os jovens estão trocando o campo pela cidade, causando desafios para a continuidade da agricultura de base familiar e a falta de mão de obra nessas localidades. Como consequência, temos o envelhecimento do meio rural (CARVALHO et. al. 2009). Isso já é visto na localidade rural Fortaleza, onde a maioria da população é formada por idosos aposentados que não utilizam o trabalho com a terra como forma de geração de renda. A agricultura é apenas para consumo próprio e escambo entre vizinhos, diferentemente do passado, 
quando a agricultura era principal fonte de renda da localidade.

Segundo o Guia Alimentar Para a População Brasileira (2014) a alimentação deve levar em conta o impacto das formas de produção e distribuição dos alimentos sobre a justiça social e a integridade do ambiente. A depender de suas características, o sistema de produção e distribuição dos alimentos pode promover justiça social e proteger o ambiente; ou, ao contrário, gerar desigualdades sociais e ameaças aos recursos naturais e à biodiversidade. A situação de dependência em poucas espécies vegetais para obtenção de alimentos de origem vegetal gera, entre outras, grande insegurança alimentar. Para diminuir essa vulnerabilidade, os parentes silvestres de plantas cultivadas, bem como as variedades crioulas, desempenham papel de extrema relevância (BRASIL, 2011). Fazer uso das espécies frutíferas nativas melhora a segurança alimentar e a nutrição humana, por meio da valorização da importância alimentícia e nutricional das espécies nativas relacionadas à agrobiodiversidade e do resgate do valor cultural (SILVA, 2015). Como sugere Pesce (2011), a grande quantidade de espécies silvestres semidomesticadas comestíveis representam as inúmeras possibilidades que teríamos em nos alimentar de forma autônoma, socioculturalmente sustentável e nutritivamente adequada.

Diante do exposto destaca-se que o presente trabalho teve como objetivo conhecer, a partir das práticas alimentares em torno das frutas nativas, como se constitui a identidade social dos moradores do distrito da Fortaleza, área rural da cidade de Cidreira, no Litoral Norte do Rio Grande do Sul.

Falar sobre identidade não é uma tarefa simples na concepção de Bauman (2005). Na constituição da identidade, as pessoas estão expostas a uma série de princípios e, por isso, em constante construção e invenção de pertencimentos. Adotandose a ideia de que as referências que identificam os sujeitos, são construídas cotidianamente em defesa de seu (re)conhecimento e (sobre)vivência coletiva em uma sociedade mais ampla e em mudança, parte-se do pressuposto que a identidade não é estática, mas em constante e contínua transformação (BAUMAN, 2005). Esse processo de transformação se fortalece pelo fato do ser humano ser portador de uma cultura e estar ligado a outros seres humanos em coletividade partilhando dessa cultura.

O texto, incluindo esta introdução, será composto, em primeiro lugar, pelo relato do caminho metodológico empreendido para gerar os dados, os participantes do estudo, o uso de técnicas e instrumentos de pesquisa e, em seguida, pela apresentação e discussão dos dados, em que se discute o modo de vida das pessoas da Fortaleza, destacando-se, a partir do consumo das frutas nativas, o passado e o presente de um pertencimento que não é estático, mas fruto das continuidades de um passado e das transformações do presente. Por fim, nas considerações finais apresenta-se, reflexões e desdobramentos que emergiram do tema, da possível continuidade deste projeto no futuro e do trajeto percorrido na pesquisa.

\section{Caminho metodológico}

Os dados foram obtidos por meio de metodologia qualitativa de pesquisa. A partir da abertura desta proposta para enfocar o contexto e incluir o universo de significados, motivos, crenças, valores e perspectivas dos sujeitos, é permitido melhor captar, descrever, interpretar e compreender os fenômenos sociais na sua densidade não só como produto, mas principalmente como processo, como construção que é dinâmica e multifacetada (MINAYO, 2008; BEAUD; WEBER, 2007).

Enquanto técnica para coleta dos dados utilizou-se o Grupo Focal (GF). Morgan (1997) descreve grupos focais como uma técnica de pesquisa qualitativa que reúne informações por meio das interações grupais. Essa, talvez, seja a principal contribuição que esta técnica poderia oferecer ao estudo, pois ao fornecer declarações e relatos sobre experiências não apenas individuais mais em um contexto interacional, ela oferece elementos para se analisar um pertencimento e identidade que, para além de singular é também uma construção social que se dá 
na interação, relação entre os sujeitos. Os recursos utilizados para a realização do grupo seguiram as orientações de Trad (2009).

Participaram do GF 11 sujeitos (4 homens e 7 mulheres, com idades entre 29 e 81 anos) integrantes da Associação Rural da localidade Fortaleza AGROCID. Esse número é perfil dos participantes do GF possibilitou, como sugere Pizzol (2004), a participação de forma efetiva de todos, a discussão detalhada dos temas propostos para o encontro, bem como os relatos dos mais velhos sobre a história da localidade e as vivencias dos mais jovens em torno da identidade local. O grupo focal ocorreu no dia 15 de novembro de 2016, teve duração de uma hora e quarenta minutos e foi coordenado por uma das autoras, como o apoio das demais, seguindo um roteiro pré-estabelecido com questões que diziam respeito ao passado, presente e previsão para o futuro, relacionando o consumo das frutas nativas com 0 modo de vida daquela população nestes três tempos. Os participantes foram dispostos em cadeiras arrumadas de forma circular e próximo a roda foi preparada uma mesa com frutas nativas da região e imagens trazidas pelos participantes e pelas autoras que, em alguma medida, foram elementos disparadores de histórias e relatos no grupo. Com a permissão dos participantes, que assinaram o termo de consentimento livre e esclarecido, a entrevista foi gravada e fotografias foram tiradas. As falas dos participantes foram transcritas, permitindo a avaliação qualitativa dos dados obtidos no processo grupal. Os nomes das pessoas foram substituídos por nomes fictícios preservando assim a identidade dos participantes.

A análise dos dados ocorreu a partir da Análise Tematizada de Conteúdo proposta por Minayo (2008). Operacionalmente, desdobrou-se nas seguintes etapas; a) pré-análise: momento em que ocorreu a leitura flutuante, constituição dos corpus, formulação e reformulação de pressupostos do estudo. Ou seja, foi o momento da imersão no material de campo, possibilitando a construção da relação entre os pressupostos iniciais, os emergentes e as bases conceituas/teóricas relacionadas ao tema.; b) exploração do material: é o momento em que buscouse encontrar as categorias relevantes e responsáveis pela especificação do tema, ou seja, expressões ou palavras significativas em função das quais o conteúdo de uma fala se organiza; c) tratamento dos resultados obtidos e interpretação: nesta fase foram realizadas as inferências e interpretações, inter-relacionando-as com quadro das referências conceituais/bibliográficas iniciais e, em alguns, com outras referências que foram buscadas e emergiram a partir de novas demandas do empírico.

\section{Resultados e discussões}

A partir da categorização das informações e fazendo um paralelo entro o consumo das frutas e vida da comunidade rural, foi possível organizar o texto em pelo menos dois eixos: o ontem e o hoje.

O ontem: um lugar com variedades de frutas nativas, diversas famílias e uma comunidade

Quando perguntado ao grupo que frutas nativas, tais como aquelas das imagens que estavam sobre a mesa, haviam no lugar e eram consumidas, os relatos foram de que, no passado, existia uma grande variedade de frutas. Muitas delas foram citadas, como, por exemplo, araçá, pitanga, butiá, guabiroba, bananado-mato, maracujá-do-mato, tuná, arumbeva, tucum, bacupari, ingá, coquinho do mato, baleeira, melãozinho (quadro 1). Todas de fato nativas, do lugar, sendo encontradas no mato, na "restinga", nos caminhos que as pessoas circulavam, como denotam as falas a seguir.

[...] mas a gente ia mais era no mato comer coquinho, araçá e pitanga. Num tempo a gente juntava uma turma e andava pelo mato. Ainda levava uns vasinhos e uns sacos pra trazer cheio de araçá (Berenice). Eu ia de a pé para o colégio aqui, quando ia daqui pra lá chegava tarde em casa, essa guabiroba do campo a gente ia comendo, maçã do campo, araçá também, ia comendo até chegar em casa, chegava tarde (Sebastião). 
Quadro 1: Lista de frutas nativas citadas pelos participantes ordenado em ordem alfabética seguindo nome cientifico e nome popular consultado no site flora digital/UFRGS*.

\begin{tabular}{|c|c|}
\hline Nome Científico & Nome(s) popular(es) \\
\hline Bactris setosa Mart. & Tucum \\
\hline $\begin{array}{l}\text { 2. Bromelia antiacantha } \\
\text { Bertol. }\end{array}$ & $\begin{array}{l}\text { Banana-do-mato, banana de } \\
\text { gravatá. }\end{array}$ \\
\hline $\begin{array}{l}\text { 3. Butia catarinensis Noblick } \\
\text { \& Lorenzi. }\end{array}$ & Butiá-da-praia. \\
\hline $\begin{array}{l}\text { 4. Butia eriospatha (Mart. ex } \\
\text { Drude) Becc. }\end{array}$ & Butiá-da-serra. \\
\hline $\begin{array}{l}\text { 5. Campomanesia } \\
\text { xanthocarpa O. Berg. }\end{array}$ & Guabiroba, guaviroba. \\
\hline $\begin{array}{l}\text { 6. Cereus hildmannianus } K \text {. } \\
\text { Schum. }\end{array}$ & Tuná \\
\hline $\begin{array}{ll}\text { 7. } & \text { Garcinia gardneriana } \\
\text { (Planch. \& Triana) Zappi. }\end{array}$ & Bacupari, bacopari \\
\hline 8. Eugenia uniflora L. & Pitanga \\
\hline 9. Momordica charantia $L$. & Melãozinho, melão são Caetano \\
\hline 10. Opuntia elata Salm-Dyck. & Arumbeva, arumbeba. \\
\hline 11. ingá vera Willd. & Ingá, ingá-banana \\
\hline 12. Passiflora actinia Hook. & Maracujá-do-mato. \\
\hline $\begin{array}{l}\text { 13. Psidium cattleianum } \\
\text { Sabine. }\end{array}$ & Araçá, araçá-amarelo. \\
\hline $\begin{array}{l}\text { 14. Syagrus romanzoffiana } \\
\text { (Cham.) Glassman. }\end{array}$ & Coquinho do mato, Jerivá. \\
\hline 15. Varronia curassavica Jacq. & Baleeira \\
\hline
\end{tabular}

* http://www.ufrgs.br/fitoecologia/florars/

Importante destacar que, as falas da existência das frutas, trazem consigo também a existência do lugar que, comum entre as pessoas e famílias e sem "cercado", como aparece na fala a seguir, formava uma unidade, formava o lugar-rural onde se compartilhava um modo de vida que os ligava uns aos outros.

Não havia cercado, a gente vinha lá de cidreira e ia até rancho velho assim, sem encontrar cerca [...]. E existia as restingas que tinha as frutas nativas [...] então ali tinha várias restingas e tinha araçá, tucum (Francisco).

Junto com as frutas, que eram várias, apareceram as lembranças e histórias das pessoas, das várias famílias que constituíam a localidade e eram por ela constituídas. A aproximadamente 30-40 anos atrás, a vida dos jovens e famílias, até mesmo nos

1 Quitandeiro, foi o termo utilizado no grupo focal para falar do trabalho dos pais e avós, que plantavam hortaliças e abasteciam, como ambulantes, os finais de semana, era intensa "no" lugar, "no campo", junto das pessoas, da natureza e dos animais.

A nossa diversão aqui no campo no domingo, na sexta - feira a gente tinha aula e já combinava com os colegas de domingo ir comer araçá, comer pitanga lá no banhado perto do Francisco, ou lá na Marta que era comer araçá, se empoleirava de dois em dois no cavalo e passava a tarde comendo (Maristela).

Lembrança, hoje o que eu mais recordo é o que a gente tem saudade daquele grupo de 20 poucas colegas, amigos, primos que iam. A gente se reunia no domingo pra comer a fruta, a gente ia até o banhado, passava a tarde no banhado (Maristela).

É no passado desse lugar, que também foi construída a base da identidade do grupo, de agricultores, de "quitandeiros" 1 , que junto do trabalho com a terra e compartilhado com a família e vizinhança, produziam e vendiam verduras e com elas mantinham seu sustento material e social. No passado, eram os quitandeiros que abasteciam o comércio local e as famílias que veraneavam no litoral, como retratam as falas a seguir.

Era assim, não tinha a estrada, então não se ia na Ceasa buscar verdura. A verdura que os veranistas conseguiam era tudo produzido aqui. O meu pai, o pai da Berenice, o pai da Paula era outra coisa era leite e carne, abastecia Cidreira, [...] chamávamos de quitandeiros, então saiam daqui as $2 \mathrm{~h}$ da madrugada e chegavam lá na praia as $5 \mathrm{~h}$ mais ou menos, e saiam de carreta, distribuindo assim, e o pessoal chegava nas carretas pra comprar (Francisco).

[...] Voltando ai as verduras, então o meu pai criou os 3 filhos e pagou meus estudos, que eu me formei professora em Osório, estudando em Osório, com o dinheiro da verdura, vendendo lá em Cidreira, vendia esses 3 meses as verduras lá e era para resto do ano [...] (Claudia).

No passado, a ligação com os grandes centros e seus valores não ocorria facilmente pela ligação por estradas, mas pelas pessoas que circulavam pelo litoral vindas de outros lugares. Por esse motivo, apreende-se que a identidade do lugar foi também

estabelecimentos e famílias do litoral do Rio Grande Do Sul, em uma época que não havia as centrais de abastecimento. 
construída em interação com os outros, da(s) cidade(s). Essa identidade foi sendo construída não como um continuum da vida na cidade. $\mathrm{Na}$ interface com o de "fora", aparece preservados valores de uma "comunidade", como demonstra um dos nossos interlocutores na transcrição a seguir. Junto aos valores como a família, o cuidado com a terra, com a comunidade/lugar, aparecem a busca pelo estudo.

Fui criado desde "pequeninho" na chácara ali, com bastante fartura e assim nós tinha uma comunidade, muitas famílias moravam aqui neste lugar e depois eles foram saindo daqui para estudar fora, casaram e foram embora morar assim, mas ainda assim mesmo nós ficamos tudo aqui e ainda temos uma família conservando nosso lugar, lidando com a natureza, plantando, cuidando e conservando esse nosso lugar (Bento).

Partindo-se da concepção de que falar do lugar, das lembranças quando havia muitas frutas é falar também de pessoas, apreende-se que, quando os informantes exaltam as características desse rural, eles estão lançando as suas qualidades, isto é, aquilo que os faz, mesmo indo "estudar fora" serem, também, singulares enquanto grupo social. Portanto, quando se faz referência às características lançadas pelos interlocutores significa discorrer sobre a identidade do grupo, uma identidade que se pode denominar de camponesa, partindo-se de uma perspectiva cultural, da qual os autores Woortmann (1990) e Sabourin (2011) são adeptos e da qual destacam-se elementos com a família e o trabalho com a terra enquanto sustentáculos da vida em comum.

Os relatos supracitados fazem com que se apreenda o lugar em seu aspecto espacial lá do passado (e do presente como se verá mais adiante), mas, também, como uma coextensão das pessoas e do seu modo de viver singular. É no lugar que acontece o mundo do vivido. É no lugar que se suspende a vida, como discute (SABOURIN, 2011)

Cabe, por fim, sublinhar, que ao se destacar os componentes das paisagens do passado, tal como as frutas nativas, os caminhos, as restingas e os matos onde elas existiam, também se despertou uma memória coletiva do passado capaz de reconstruir e dar visibilidade ao espírito do lugar, ao espírito de uma grupalidade e, o mais importante, à possibilidade de reconstruir um futuro diante das crises (econômicas, sociais, culturais e ambientais) de um modelo produtivista na agricultura. Como discute Carneiro (1998), um grupo que não tem memória de seu passado tem também dificuldades de recriar e desdobrar a imaginação de seu futuro.

No hoje resistindo: menos frutas, menos famílias, mas a Fortaleza permanece em (re)construção

A fala de um dos participantes do GF, na transcrição que trouxemos na seção anterior, ilustra o fato de muitas famílias terem saído do lugar para estudar, terem casado e ir morar na cidade ou até mesmo em outros lugares. As famílias, assim como as frutas nativas, foram diminuindo ao longo do tempo, poucas ficaram residindo permanentemente no lugar, mantendo a comunidade. Para se sustentar no presente, a natureza, assim como a comunidade, vem pedindo socorro, como relata Sebastião.

O araçá quando eu era mais novo lá na minha chácara, começava ali na Marta o mato e a lagoa lá, o araçá tu apanhava um balde, dois balde, era fácil. Hoje não tem quase, tem os pés, mas não tem as frutas, a natureza está pedindo socorro (Sebastião).

No entanto, é importante destacar que, a comunidade rural busca e tem encontrado formas de resistir, de continuar a existir. A Fortaleza continua protegendo o espírito de grupo, a natureza e a sociobiodiversidade, como discutiremos nessa seção. As pessoas saíram, algumas permaneceram parcialmente residindo nos finais de semana, mas hoje, até mesmo as mais jovens, estão fazendo movimentos de retorno. A resistência/permanência aparece quando as pessoas dizem que saem do lugar, mas o lugar não saiu delas e, assim, a identidade da Fortaleza vai sendo defendida.

Nasci e me criei aqui, em oitenta fui pra Cidreira para dar estudo para os filhos, por que aqui não tinha, era só terceira série, me obriguei a me mudar para lá, para Cidreira. Mas tenho minha chácara aqui, amo esse lugar aqui, que eu nasci e me criei aqui, amo essa terra, então estou lá em Cidreira, mas fim de semana eu venho para a minha chácara aqui (Berenice).

Mas ao sair de Cidreira a Cidreira, a Fortaleza nunca saiu de nós, sempre nos 
acompanhou. E foi muito bom essas andanças, mas as horas mais felizes foram aquelas de voltar (Francisco).

[...] $\mathrm{Na}$ verdade, que nem diz a tia, o coração é daqui, a gente adora estar aqui, é uma paz que traz pra gente, o lugar é maravilhoso, então eu tenho satisfação de dizer que eu sou daqui por que eu amo estar aqui (Carolina).

Algumas famílias que ficaram e, principalmente as que saíram e agora fazem movimentos de retorno, retornam diferentes. A identidade, assim, resiste, contudo não é estática, passiva frente aos movimentos da sociedade em que se insere. Mas, como defende Carneiro (1998), há adaptação às novas dinâmicas da sociedade mais ampla sem, contudo, abrir mão de valores e visões de mundo característicos do lugar.

Aparece junto dos valores, da tradição, do pertencimento, discursos que marcam um modo de vida dinâmico em constante (re)construção. Um modo de vida que valoriza o trabalho com a terra, o cuidado com a família - com a comunidade -, mas também o conhecimento de dentro e que o contato com o de fora podem trazer, como aqueles relacionados ao meio ambiente, a saúde e a comida, como destacamos nas falas a seguir.

\begin{abstract}
Mas o bacupari eu tive lendo qualquer coisa na internet que ele tem uma propriedade anticancerígena. Assim por excelência, diz que a frutinha que tinha mais esse teor é goji Berry nos Estados Unidos e ai eles descobriram o bacupari aqui que tem assim 3 vezes mais esse teor. Eu me entusiasmei muito com ele, então esse ano eu fui lá na casa do Sebastião e peguei o bacupari, bastante semente, vou plantar agora, toda a área, e na Berenice, eu descobri que no pátio da Berenice tem uma frondosa árvore de bacupari, tão grande (Francisco).

Hoje eu aprendi diferente além de comer no pé que nem passarinho que gosta de comer no pé, eu uso a fruta no sorvete, descobri que a pitanga dá pra fazer sorvete de pitanga que é uma delícia, na cuca, tu pode botar na cuca o cremezinho da pitanga, do araçá, aquele antes da farofa (Maristela).
\end{abstract}

O lugar Fortaleza aparece não somente como espaço produtivo dos antigos quitandeiros, que utilizavam a terra para plantar, vender e manter a reprodução material e social. Fortaleza é também lugar de vida, de cuidado de si e do ambiente, possivelmente mais valorizado que antes como tal, como aparece ao se falar das frutas: "Hoje nós estamos dando mais valor a nossas frutas, né?" (Maristela). Valorizado pois é tempo de resistir, é preciso valorizar como espaço de vidas para não sucumbir no meio de monocultivos, como de pinus, que estão transformando a paisagem do entorno, sua fauna, flora e empurrando as pessoas para fora, como se percebe.

O que eu lembrei agora em razão de, não sei talvez, por ter se terminado essas frutas, por que antes era tudo mato e depois com essas plantação de pinus, foram tudo sendo desmatado pra plantar pinus por todos os lados [...] (Cecília).

E outra coisa, como eu disse era tudo aberto, agora é tudo fechado, tudo são propriedades fechadas, então não é assim da gente se juntar uma turma e ir lá, tem que pedir licença, para entrar lá e ir comer, não é como antes que era tudo aberto, que juntava turma, né? (Francisco).

Do ponto de vista gramatical no seu sentido estrito, a palavra "Fortaleza" pode significar "fortificação", "solidez", "segurança", "lugar bem defendido" (FERREIRA,1999). Algo importante de se destacar é que esse é também o significado que esse espaço rural tem para as pessoas. "Fortaleza" é o nome da localidade e é igualmente a relação que seus moradores têm com o lugar. Hoje, valorizar práticas, proteger as frutas, manter as chácaras e plantações, mesmo que não seja para vender em proporções grandes, como faziam os quitandeiros do passado, é também defender o lugar, proteger uma identidade rural, um pertencimento.

O pessoal que ficou aqui fora nas chácaras, que são saudosistas, eu, a Berenice, a Paula..., nós ficamos aqui, mas nós plantamos verduras mais para sobrevivência, alimentar os próprios animais. Praticamente a gente não vende mais como a gente vendia aqueles produtos (Francisco).

Enfim, uma análise possível de ser realizada é que esse rural, assim como tantos outros, é um espaço dinâmico, pluriativo, não somente de produção agrícola e que, não se opõe ao urbano, não o nega, se conecta a ele, como discute Wanderely (2001). As pessoas (que lá vivem ou que moram na cidade e têm usado o lugar nos finais de semana) falam em cuidar 
das frutas, e assim do lugar, para não deixar acabar um modo de vida e um espaço que mantém uma paisagem, um patrimônio vegetal, social e capaz de, no presente e no futuro, promover e ser o sustentáculo de práticas alimentares mais saudáveis e diversas para o campo e para a cidade.

E agora a gente tá vendo o quanto está se acabando, a cada ano que passa menos fruta vai tendo no pé, então a gente resolveu esse ano começar a podar pra ver se a gente consegue resgatar um pouco, por que tem muitos pés que são bem velhos ali assim, que a gente lembra da adolescência assim, então a gente resolveu fazer isso pra ver se a gente resgata a fruta né? (Carolina).

Além de comer no pé, né? Que é muito gostoso, fazer um grupo e ir direto comer no pé que é muito divertido né? Mas hoje nós podemos fazer, sorvete, a geleia, a chimia, a calda, faz um bolo que tá na época agora, Sorvete de butiá, sorvete de pitanga. O suco, que eu chego a guardar as polpas no congelador, no freezer que é para durar pro inverno. (Maristela).

\section{Considerações finais}

Analisando as falas dos interlocutores concluise que o consumo de frutas nativas (como se come, onde e com quem se come) contribuiu para a formação da cultura da população da Fortaleza e que este local hoje não é mais um local para garantir o sustento, mas sim um lugar para preservar a identidade da comunidade. Identidade está que é demonstrada pelo grupo e pela fala de um dos participantes "ainda temos uma família conservando nosso lugar, lidando com a natureza, plantando, cuidando e conservando esse nosso lugar", família, que é toda a população rural da Fortaleza, contato com a natureza e preservar o local é o que dá forma a comunidade.

Podemos analisar, a partir das histórias em torno das frutas nativas, as histórias do passado e de como mudou a paisagem desta região de ontem para hoje. Atualmente, o monucultivo do pinus, e o início da plantação de soja, estão tomando conta da paisagem, podendo levar ao desaparecimento das frutas nativa, da fauna e da flora da região, da comunidade e do lugar. Com tudo, surge a vontade de resgatar, de plantar essas árvores frutíferas que existiam na região, como forma de preservar a paisagem, o ambiente, a cultura e a história do local. As frutas têm se tornado algo que inspira ações futuras não só como forma de resgate, mas também de valorização, de (re)construção desta comunidade rural.

\section{Referências}

1 AMON, D. ; MENASCHE, R. Comida como narrativa da memória social. Sociedade e Cultura, v.11, n.1. 2008. pg 13 a 21.

2 BAUMAN, Z. Identidade. Rio de Janeiro: Jorge Zahar, 2005. 112p.

3 BEAUD, S. ; WEBER, F. Guia para a pesquisa de campo: produzir e analisar dados etnográficos. Petrópolis: Vozes, 2007. 192p.

4 BRASIL, Ministério da Saúde. Secretaria de Atenção à Saúde. Departamento de Atenção Básica. Guia alimentar para a população brasileira. 2 ed, Brasília/DF, Ministério da Saúde, 2014.

$5 \quad$ BRASIL. Ministério do Meio Ambiente. Espécies Nativas da Flora Brasileira de Valor Econômico Atual ou Potencial: plantas para o Futuro - Região Sul. Brasilia/DF, 2011.

6 CARLOS, A. F. A. O lugar no/do mundo. São Paulo. FFLCH, 2007. 85p. 1 ed. Disponível em: $<$ http://gesp.fflch.usp.br/sites/gesp.fflch.usp.br/fil es/O_lugar_no_do_mundo.pdf >

7 CARNEIRO, M. J. Ruralidade: novas identidades em construção. Estud.Soc.Agric, Rio de Janeiro, n. 11, p. 53-75, out. 1998.

8 CARVALHO, D. M. et al. Perspectivas dos jovens rurais: campo versus cidade. Sociedade Brasileira de Economia, Administração e Sociologia Rural. Porto Alegre, 2009.

9 FERREIRA, Aurélio Buarque de Holanda. Novo Dicionário da Língua Portuguesa. $3^{a}$ ed. Rio de Janeiro: Nova Fronteira, 1999. p. 932.

10 OMACIEL, M. E. Identidade cultural e alimentação. In CANESQUI, Ana Maria; GARCIA, Rosa Wanda Diez; orgs. Antropologia e nutrição: um diálogo possível. Rio de Janeiro: Editora FIOCRUZ, 2005. 306 p. Antropologia e Saúde collection.

11 MINAYO, M. C. S.O desafio do conhecimento: pesquisa qualitativa em saúde. 11. ed. São Paulo: Hucitec, 2008. 406p.

12 WANDERLEY, M. N. A ruralidade no Brasil moderno. Por um pacto social pelo 
desenvolvimento rural. In: GIARRACA, Norma. ¿UNA NUEVA RURALIDAD EN AMÉRICA LATINA? Buenos Aires, 2001. Cap 2, p.31 - 44.

13 MORGAN, D. L. Focus Groups as qualitative research. 2 ed. Londres: A sage university paper, 1997. 80p.

14 PESCE, L. C. Levantamento etnobotânico de plantas nativas e espontâneas no RS: conhecimento dos agricultores das feiras ecológicas de Porto Alegre. 2011. 51f. Trabalho de conclusão de curso (Graduação em Ciências Biológicas) - Instituto de biociências, UFRGS, Porto Alegre, 2011.

15 PIZZOL, S. J. S. Combinação de grupos focais e análise discriminante: um método para tipificação de sistemas de produção agropecuária. Revista de Economia e Sociologia Rural, vol.42, no.3 Brasília, 2004.

16 SABOURIN, E. Sociedades e organizações camponesas: uma leitura através da reciprocidade. Porto Alegre: Ed. da UFRGS, 2011. 272p.

17 SILVA, V. L. et.al. Análise da Composição Nutricional de Frutos de Plantas Nativas da Região Sul do Brasil e formulação de receitas. Em fase de elaboração. Porto Alegre, 2015.

18 TRAD, L. A. B. Grupos focais: Conceitos, procedimentos e reflexões baseadas em experiências com o uso da técnica em pesquisas de saúde. Physis: revista de saúde coletiva, v. 19, n. 3, p. 777-796, Rio de Janeiro, 2009.

19 WOORTMANN, K. Com parentes não se negucia: o campesinato como ordem moral. Anuário Antropológico. v. 87, p. 1173. Brasília. 1990. 